\title{
Elevated preoperative neutrophil-to- lymphocyte ratio predicts early adverse outcomes in uncomplicated type B aortic dissection undergoing TEVAR
}

\author{
Hongqiao Zhu ${ }^{\dagger}$, Lei Zhang ${ }^{\dagger}$, Taiping Liang ${ }^{\dagger}$, Yiming Li, Jian Zhou ${ }^{*}$ and Zaiping Jing ${ }^{*}$ (1)
}

\begin{abstract}
Background: Thoracic aortic endovascular repair (TEVAR) of uncomplicated type B aortic dissection (UTBAD) has favorable long-term outcomes but higher early adverse events compared with the optimal medical treatment. Recently, clinical evidence concerning vascular surgery indicates that elevated preoperative systemic inflammatory response predicts adverse clinical events. The aim of our study was to evaluate the relationship between preoperative neutrophil-to-lymphocyte ratio (NLR) and early outcomes of UTBAD patients undergoing TEVAR.

Results: 216 patients diagnosed with UTBAD were included in this retrospective study between January 2015 and December 2018. The median (IQR) follow-up period was 21 (15-33) months. An early adverse event was defined as occurring within 2 years after the procedure. Median patient age was 60 (IQR, 48-68) years and $78.7 \%$ were male. Early adverse events occurred in 24 patients (11.1\%). In the multivariable analysis, preoperative NLR (HR per SD, 1.98; $95 \% \mathrm{Cl}, 1.14-3.44 ; P=0.015$ ) was associated with 2-year adverse events.

Conclusions: NLR is an independent predictive factor of early adverse events in UTBAD patients undergoing TEVAR.

Keywords: Neutrophil-to-lymphocyte ratio, Thoracic endovascular aortic repair, Uncomplicated type B aortic dissection, Systemic inflammatory response, Inflammatory markers
\end{abstract}

\section{Background}

Acute type B aortic dissection (TBAD), one kind of acute aortic syndromes, featured with sudden onset, rapid progression, and high mortality $[1,2]$. Despite its name, "uncomplicated" TBAD (uTBAD) is still a problematic disorder that is associated with high long-term mortality when treated medically alone [3]. With the advantages in exclusion of primary entry tear and remodeling of affected aorta, thoracic endovascular aortic repair

\footnotetext{
*Correspondence: zhoujian1-2@163.com; jingzaiping_vasc@163.com ${ }^{\dagger}$ Hongqiao Zhu, Lei Zhang and Taiping Liang have contributed equally to this work

Department of Vascular Surgery, Changhai Hospital, Navy Medical University, Shanghai 200433, China
}

(TEVAR) was attempted in the UTBAD combined with optimal medical treatment [4]. Clinical researches based on retrospective cohort suggest that TEVAR is beneficial in long-term outcomes for uTBAD $[3,5]$.

However, there are still debates about the endovascular repair of uTBAD because of disappointing early outcomes compared with optimal medical treatment [6]. Recently, there has been a significant body of work which has investigated the use of systemic inflammatory marker neutrophil-to-lymphocyte ratio (NLR) to both prognosticate patients and to guide treatment [7-9]. In a cross-section study containing 1021 patients receiving major vascular surgery, elevated preoperative NLR (>5) was an independent risk factor of 2-year 
mortality [10]. It would therefore be of great interest to clearly define the association with baseline NLR and early clinical outcomes in UTBAD patients undergoing TEVAR.

The study aimed to determine whether elevated baseline NLR is correlated to early poor outcomes of UTBAD patients after TEVAR.

\section{Methods}

\section{Patient selection}

A total of 216 consecutive patients at the Department of Vascular and Endovascular Institution (Changhai Hospital, Shanghai, China) who underwent TEVAR of their primary uTBAD between January 2015 and December 2018 were included in the current study.

Overall exclusion criteria were: patients who were $<18$ years old; had aortic dissection secondary to iatrogenic injury, trauma, intramural hematoma or penetrating aortic ulcer; had genetic disease such as Marfan syndrome or Ehlers-Danlos syndrome [11].

Additionally, the following susceptible factors and clinical conditions that may affect baseline systemic inflammatory status or postoperative status were excluded: (1) Patients with proximal landing zone 1 demanding for a hybrid or multi-fenestration technique; (2) Any peripheral artery disease or coronary artery disease being treated with dual anti-platelet therapy; (3) Any malignant disease or end-stage disease like uremia; (4) Any chronic infectious disease being treated with antibiotics; (5) Any autoimmune disease being treated with glucocorticoid [12].

According to the criteria above, 33 patients were excluded, which composed of 5 cases diagnosed with Marfan Syndrome, 8 cases diagnosed with cancer, 12 cases treated with hybrid technique, 1 case with AMI treated with dual anti-platelet therapy, 3 cases treated with dialysis and 4 cases suspected with signs of infection.

Computed tomography angiography (CTA) examinations were performed before the operation to evaluate characteristics of aortic dissection. The follow-up period ended on February 1, 2020.

\section{Medical management}

Medical treatment aimed to relieve the stress of aortic adventitia and reduce the volume of false lumen [6]. Aggressive antihypertensive therapy by oral or intravenous route was used to keep the systolic blood pressure $<120 \mathrm{mmHg}$ and the heart rate $<70$ beat $/ \mathrm{min}[6$, 11]. Adequate analgesia was administered when patients still felt pain after antihypertensive therapy.

\section{TEVAR procedure}

All patients received general anesthesia in order to administrate blood pressure and heart rate during the procedure. All procedures were performed with patients using total endovascular techniques under fluoroscopic guidance. The proximal landing zone was considered to be at least $>2 \mathrm{~cm}$ [13] If the landing zone was inadequate, reconstruction of the left subclavian artery (LSCA) was performed to preserve the blood of the brain and reduce the complications [14].

\section{Follow-up}

Patients were advised to check up annually in our hospital. Health conditions of patients who did not return were contacted via telephone.

\section{Baseline blood count}

Samples of 216 patients' complete blood count with differential 24 hours before the TEVAR procedure were accessed from the electronic medical record in Changhai Hospital.

\section{Statistics analysis}

Continuous variables were expressed as the mean \pm standard deviation or median (with interquartile range, IQR); categorical variables were expressed as frequencies and percentages. A time-dependent receiver operating characteristic (ROC) curve was utilized to identify a cut-off value NLR associated with 2 -year adverse events. Study cohort was then divided into two groups by cut-off value of NLR 4.8. Patients were then grouped into 'low NLR' $(<4.8)$ and 'high NLR' ( $\geq 4.8$ ) groups to identify the differences of clinical characteristics and outcomes. Difference between the two groups were compared by Student's t-test or Mann-Whitney $U$ test for Continuous variables and a chi-square test for categorical variables. To analyze the relationship between variates and outcomes, univariate and multivariate Cox proportional hazards regression models was used. Variables found to be susceptive $(\mathrm{P}<0.2)$ in univariate analysis were entered into a Cox regression multivariate model using a backwards conditional method. A P value $<0.05$ was considered statistically significant and all estimates were two-tailed. All analyses were performed with $\mathrm{R}$ (http://www.R-proje ct.org) and Empower Stats software (www.empowersta ts.com, X\&Y Solutions, Inc., Boston, MA, USA).

\section{Definition of terms and outcomes}

Phase of TBAD was according to the VIRTUE Registry and ESC guideline $[4,11]$. "Uncomplicated" is a relatively stable status administrated by optimal medicine, 
on which the patients are expected to survive without severe comorbidities $[11,15]$. The definition of procedure success was to exclude the primary entry tear in the premise that there was no type I or III endoleak at the end of the operation. Post-implantation syndrome (PIS) was defined as fever $>38{ }^{\circ} \mathrm{C}, \mathrm{WBC}>12.0 / \mathrm{nl}$ and CRP $>10 \mathrm{mg} / \mathrm{dl}$ within 3 days after TEVAR despite negative blood culture results [16]. The definition of an early adverse event was occurrence within 2 years after the procedure. The primary endpoint was early adverse events, which included all-cause mortality, type I/II endoleak, retrograde aortic dissection (RTAD), stent graft-induced new entry (SINE), paraplegia, major stroke, aortic rupture.

\section{Results}

\section{Baseline characteristics}

The median follow-up time was 21 months (interquartile range, IQR 15-33). The baseline characteristics of this cohort are documented in Table 1 . Briefly, $50 \%$ of patients were older than $60,21.3 \%$ were females. Additional characteristics of the patients included smoking in $27.8 \%$, alcohol use in $18.1 \%$, hypertension in $66.2 \%$, diabetes in $4.6 \%$, chronic obstructive pulmonary disease (COPD) in $3.7 \%$, renal insufficiency in $5.1 \%$, stroke in $4.6 \%$, and coronary artery disease (CAD) in $6.5 \%$ (Table 1). For the inflammatory status, $48.1 \%$ had high NLR and 51.9\% had low NLR (Table 1). Significant differences was shown between the high and low NLR group in median age (year) ( 54 vs. $62 ; P=0.018)$, portion of partial thrombosis $(\%)(30.8 \%$ vs. $16.1 \% ; P=0.02)$, median systolic blood pressure on admission $(\mathrm{mmHg}$ ) (148 vs. $140 ; P=0.007)$, median serum creatinine before procedure $(\mu \mathrm{mol} / \mathrm{l})(81$ vs. $76 ; P=0.036)$, median platelet count before procedure $\left(\times 10^{9} / \mathrm{l}\right)(170$ vs. $221 ; P<0.001)$ (Table 1).

\section{Medical managements}

Details of medical treatment was shown in Table 2 . There was no difference between the two groups except calcium-channel blockers (high NLR group vs. low NLR group, $84.6 \%$ vs. $69.6 \%, P=0.009$ ).

\section{TEVAR procedure}

27 adjunctive stents were implanted to reconstruct the LSCA. Details of the procedure were shown in Table 3.

\section{Early adverse events}

There were no in-hospital adverse events in either group. PIS occurred in 8 (3.7\%) of 216 patients with no difference between the two groups $(4.8 \%$ for high NLR group and $2.7 \%$ for low NLR group, $P=0.41$ ). None of the patients above suffered from the adverse events within 2-year follow up.

Early adverse events occurred in 24 patients (11.1\%), which included one mortality due to stroke, 13 cases of type I /II endoleak, 5 cases of retrograde aortic dissection, 4 cases of aortic rupture (two died and the others survived after re-intervention) and one case of stent graft-induced new entry. The overall probability of freedom from adverse events in the high NLR group at 2 years were $82.7 \%$ while low NLR group was $94.6 \%$ $(P=0.005)$. (Fig. 1$)$.

Univariate and multivariable Cox-hazard regression analyses of early adverse events in the study population were shown in Table 4. Univariate analysis indicated that platelet count preoperatively, preoperative diastolic blood pressure and NLR preoperatively were the susceptive risk factors for early adverse events $(P<0.2)$. Multivariable regression analysis showed that the NLR preoperatively (HR per SD, 1.98; 1.14-3.44; $P=0.015$ ), diastolic blood pressure on admission (HR, 0.86; $95 \% \mathrm{CI}, 0.78-0.95$; $P=0.003$ ) had independent influences on 2-year overall event-free survival.

\section{Discussion}

The aim of this study was to evaluate the relationship between preoperative NLR and early outcomes of TEVAR. For every increase of one SD in preoperative NLR value, the risk of early adverse events increased by $98 \%$ (95\% CI, 1.14-3.44) in the multivariate adjusted model. To the best knowledge of us, this is the first research to access the predictive role of NLR in the uTBAD patients receiving TEVAR with a cut-off value 4.8.

Although long-term safety and efficacy of TEVAR have been confirmed with multiple studies [3, 5, 17], early adverse events still attract controversy and impede the extensive application of TEVAR in uTBAD. In 2019, Professor Adams and his colleagues [6] suggested that highrisk subgroup of uTBAD patients may benefit from early intervention. However, most areas in China do not have a sound medical system, which would bring difficulties to follow-up and timely risk assessment of aortic dissection. It is therefore of great value to determine the optimal timing of TEVAR procedure to evade the early adverse events.

Previous studies focused on the association between NLR value and poor clinical outcomes of type A aortic dissection (TAAD) or severe aortic events after TEVAR or open surgery $[18,19]$. Lafçi et al. [20] conducted a study with 123 patients and found that a high pre-NLR was associated with in-hospital mortality with a cut-off value 8 . In another study, Bedel et al. [21] also observed an association between high levels of admission PLR and 
Table 1 The baseline preoperative characteristics of UTBAD patients receiving TEVAR grouped by NLR value $<4.8$ and $\geq 4.8$

\begin{tabular}{|c|c|c|c|c|c|}
\hline Variable & Overall & $\begin{array}{l}\text { Low NLR } \\
(<4.8)\end{array}$ & $\begin{array}{l}\text { High NLR } \\
(\geq 4.8)\end{array}$ & $\begin{array}{l}\text { Standardized } \\
\text { difference }\end{array}$ & $P$ value \\
\hline N (\%) & 216 & $112(51.9 \%)$ & $104(48.1 \%)$ & & \\
\hline Age (year) & $60(48-68)$ & $62(50-70)$ & $54(46-66)$ & 0.32 & 0.018 \\
\hline Age group (year) & & & & 0.27 & 0.146 \\
\hline$<40$ & $20(9.3 \%)$ & $10(8.9 \%)$ & $10(9.6 \%)$ & & \\
\hline $40-60$ & 88 (40.7\%) & $39(34.8 \%)$ & $49(47.1 \%)$ & & \\
\hline$\geq 60$ & $108(50.0 \%)$ & $63(56.3 \%)$ & $45(43.3 \%)$ & & \\
\hline Male & $170(78.7 \%)$ & $83(74.1 \%)$ & $87(83.7 \%)$ & 0.24 & 0.087 \\
\hline BMI & $24.9(3.9)$ & $24.9(4.0)$ & $25.0(3.8)$ & 0.04 & 0.764 \\
\hline Smoking & $60(27.8 \%)$ & $30(26.8 \%)$ & $30(28.9 \%)$ & 0.05 & 0.736 \\
\hline Drinking & 39 (18.1\%) & $20(17.9 \%)$ & $19(18.3 \%)$ & 0.01 & 0.937 \\
\hline Hypertension & $143(66.2 \%)$ & $73(65.2 \%)$ & $70(67.3 \%)$ & 0.05 & 0.741 \\
\hline Diabetes & $10(4.6 \%)$ & $5(4.5 \%)$ & $5(4.8 \%)$ & 0.02 & 0.904 \\
\hline COPD & $8(3.7 \%)$ & $3(2.7 \%)$ & $5(4.8 \%)$ & 0.11 & 0.408 \\
\hline Renal insufficiency & $11(5.1 \%)$ & $8(7.1 \%)$ & $3(2.9 \%)$ & 0.2 & 0.155 \\
\hline Coronary artery diseases & $14(6.5 \%)$ & $9(8.0 \%)$ & $5(4.8 \%)$ & 0.13 & 0.336 \\
\hline Stroke & $10(4.6 \%)$ & $4(3.6 \%)$ & $6(5.8 \%)$ & 0.10 & 0.442 \\
\hline Dissection morphology & & & & 0.04 & 0.747 \\
\hline Confined in thoracic aorta & $56(25.9 \%)$ & $28(25.0 \%)$ & $28(26.9 \%)$ & & \\
\hline Extended to abdominal aorta & $160(74.1 \%)$ & $84(75.0 \%)$ & $76(73.1 \%)$ & & \\
\hline False lumen patency & & & & 0.38 & 0.021 \\
\hline Patent false lumen & $156(72.2 \%)$ & $90(80.4 \%)$ & $66(63.5 \%)$ & & \\
\hline Partial thrombosis & $50(23.2 \%)$ & $18(16.1 \%)$ & $32(30.8 \%)$ & & \\
\hline Complete thrombosis & $10(4.6 \%)$ & $4(3.6 \%)$ & $6(5.8 \%)$ & & \\
\hline Symptoms on admission & & & & 0.09 & 0.81 \\
\hline Chest/back pain & $156(72.2 \%)$ & $79(70.6 \%)$ & $77(74.0 \%)$ & & \\
\hline Abdominal pain & $52(24.1 \%)$ & $29(25.9 \%)$ & $23(22.1 \%)$ & & \\
\hline Other symptoms & $8(3.7 \%)$ & $4(3.6 \%)$ & $4(3.9 \%)$ & & \\
\hline Location of the primary entry tear & & & & 0.16 & 0.231 \\
\hline$>2 \mathrm{~cm}$ from the $\mathrm{LSCA}$ & $169(78.2 \%)$ & $84(75.0 \%)$ & $85(81.7 \%)$ & & \\
\hline$\leq 2 \mathrm{~cm}$ from the $\mathrm{LSCA}$ & $47(21.8 \%)$ & $28(25.0 \%)$ & $19(18.3 \%)$ & & \\
\hline Maximum diameter of thoracic aorta (mm) & $\begin{array}{l}40.7 \\
(35.2-44.3)\end{array}$ & $39.7(35.0-44.1)$ & $40.8(36.5-44.3)$ & 0.09 & 0.517 \\
\hline Maximum diameter of abdominal aorta (mm) & $\begin{array}{l}28.7 \\
(26.6-32.9)\end{array}$ & $28.5(26.5-32.4)$ & $29.4(26.6-32.9)$ & 0.16 & 0.248 \\
\hline SBP on admission (mmHg) & $143(132-154)$ & $140(130-150)$ & $148(136-157)$ & 0.37 & 0.007 \\
\hline DBP on admission (mmHg) & $80(75-89)$ & $82(75-89)$ & $80(75-88)$ & 0.04 & 0.77 \\
\hline Temperature preoperatively $\left({ }^{\circ} \mathrm{C}\right)$ & $\begin{array}{l}36.6 \\
(36.4-36.8)\end{array}$ & $\begin{array}{l}36.6 \\
(36.4-36.9)\end{array}$ & $\begin{array}{l}36.6 \\
(36.4-36.8)\end{array}$ & 0.24 & 0.077 \\
\hline Creatinine preoperatively $(\mu \mathrm{mol} / \mathrm{l})$ & $79(64-91)$ & $76(59-86)$ & $81(65-95)$ & 0.29 & 0.036 \\
\hline Platelet count preoperatively $\left(\times 10^{9} / \mathrm{l}\right)$ & $200(152-272)$ & $221(169-302)$ & $170(149-225)$ & 0.42 & 0.003 \\
\hline
\end{tabular}

Categorical variables are reported as frequency and percentage; continuous variables are reported as median (25th-75th percentile) UTBAD uncomplicated type B aortic dissection, TEVAR thoracic endovascular aortic repair, NLR neutrophil-to-lymphocyte ratio, BMI body mass index, COPD chronic obstructive pulmonary disease, LSCA left subclavian artery, SBP systolic blood pressure, DBP diastolic blood pressure

NLR and high mortality and organ dysfunction in acute TAAD patients. The studies above implied that combinations of inflammatory markers have a satisfied predictive capability for the in-hospital mortality. In contrast, in a large sample cohort study of 744 patients with TAAD, combinations of platelet, neutrophil and lymphocyte were unable to predict 30-day mortality [22]. Interestingly, when investigators combined all three biomarkers 
Table 2 The details of medical managements grouped by NLR value $<4.8$ and $\geq \mathbf{4 . 8}$

\begin{tabular}{|c|c|c|c|c|c|}
\hline Variable & Overall & Low NLR $(<4.8)$ & High NLR ( $\geq 4.8$ ) & Standardized difference & $P$ value \\
\hline Alpha-blockers & 166 (76.9\%) & $87(77.7 \%)$ & $79(76.0 \%)$ & 0.04 & 0.765 \\
\hline Beta-blockers & $140(64.8 \%)$ & $69(61.6 \%)$ & $71(68.3 \%)$ & 0.14 & 0.306 \\
\hline ARBs & 78 (36.1\%) & $43(38.4 \%)$ & $35(33.7 \%)$ & 0.1 & 0.469 \\
\hline ACEls & $32(14.8 \%)$ & $15(13.4 \%)$ & $17(16.4 \%)$ & 0.08 & 0.542 \\
\hline CCBs & $166(76.9 \%)$ & $78(69.6 \%)$ & $88(84.6 \%)$ & 0.36 & 0.009 \\
\hline Statins & $86(39.8 \%)$ & $44(39.3 \%)$ & 42 (40.4\%) & 0.02 & 0.869 \\
\hline
\end{tabular}

Values are $\mathrm{n}(\%)$

ARBs angiotensin II receptor blockers, ACEls angiotensin-converting enzyme inhibitors, CCBs calcium-channel blockers, NLR neutrophil-to-lymphocyte ratio

Table 3 The details of TEVAR procedure grouped by NLR value $<4.8$ and $\geq \mathbf{4 . 8}$

\begin{tabular}{|c|c|c|c|c|c|}
\hline Variable & Overall & $\begin{array}{l}\text { Low NLR } \\
(<4.8)\end{array}$ & $\begin{array}{l}\text { High NLR } \\
(\geq 4.8)\end{array}$ & $\begin{array}{l}\text { Standardized } \\
\text { difference }\end{array}$ & $P$ value \\
\hline Length of hospital stay (days) & $10(8-14)$ & $10(7-14)$ & $10(9-15)$ & 0.24 & 0.076 \\
\hline Timing of procedure & & & & 0.05 & 0.713 \\
\hline Acute phase & $126(58.3 \%)$ & $64(57.1 \%)$ & $62(59.6 \%)$ & & \\
\hline Subacute phase & $90(41.7 \%)$ & $48(42.9 \%)$ & $42(40.4 \%)$ & & \\
\hline ASA Classification & & & & 0.24 & 0.205 \\
\hline 1 & $68(31.5 \%)$ & $33(29.4 \%)$ & $35(33.7 \%)$ & & \\
\hline$\|$ & $140(64.8 \%)$ & $77(68.8 \%)$ & $63(60.6 \%)$ & & \\
\hline III & $8(3.7 \%)$ & $2(1.8 \%)$ & $6(5.7 \%)$ & & \\
\hline Length of procedure (minutes) & $95(75-110)$ & $95(80-122)$ & $85(72-105)$ & 0.31 & 0.025 \\
\hline \multicolumn{6}{|l|}{ Types of stentgraft } \\
\hline Cook Zenith & $93(43.1 \%)$ & $48(42.9 \%)$ & $45(43.3 \%)$ & 0.4 & 0.044 \\
\hline Gore TAG & $54(25.0 \%)$ & $33(29.4 \%)$ & $21(20.2 \%)$ & & \\
\hline Medtronic Valiant & $55(25.5 \%)$ & $21(18.8 \%)$ & $34(32.7 \%)$ & & \\
\hline Microport Hercules & $14(6.4 \%)$ & 10 (8.9\%) & $4(3.9 \%)$ & & \\
\hline Adjunctive stents & $27(12.5 \%)$ & $15(13.4 \%)$ & $12(11.5 \%)$ & 0.06 & 0.681 \\
\hline
\end{tabular}

Values are median (25th-75th percentile) or $\mathrm{n}(\%)$

TEVAR thoracic endovascular aortic repair, NLR neutrophil-to-lymphocyte ratio, ASA American Society of Anesthesiologists

(platelet counts, lymphocyte-to-neutrophil ratio and lymphocyte monocyte ratio) in the predictive model, it provided the strongest predictive value of 30-day mortality. The reason behind this apparent contradiction might be unclear time of NLR measurement. In these studies, Azab et al. [23] used average NLR during the inpatient stay in the prediction model rather than admission, discharge, or maximum NLR. On the contrary, Park et al. [24] suggested that 24-hour NLR had a better predictive value of in-hospital mortality than the admission NLR. When compared with TAAD, TBAD showed less early postoperative mortality and complications such as renal insufficiency, liver insufficiency, and gastrointestinal hemorrhage. uTBAD Patients with strict blood pressure and heart rate control have a longer life expectancy and deserve an elective surgery instead of emergent one. King et al. [9] highlighted the importance of detection and treatment of high immune or inflammatory response in the endovascular aortic repair (EVAR) of elective abdominal aortic aneurysm (AAA). In this context, NLR 24 hours before operation is a better predictive index compared with the admission one. In our study, inflammatory index 24 hours before operation was utilized to predict the adverse events. We found significant difference of early outcomes between the high NLR group and low NLR group (adverse events, 17.3\% vs. 5.4\%, $P=0.005)$ despite that systemic inflammatory response of uTBAD is relatively lower than complicated aortic dissection or type A aortic dissection considering the lesion and comorbidities.

Although previous clinical evidence has clearly shown that the increased NLR value is associated with poor outcomes after endovascular repair, the cut-off value varies among studies $[8,10,19,25,26]$. Octeau et al. [27] 


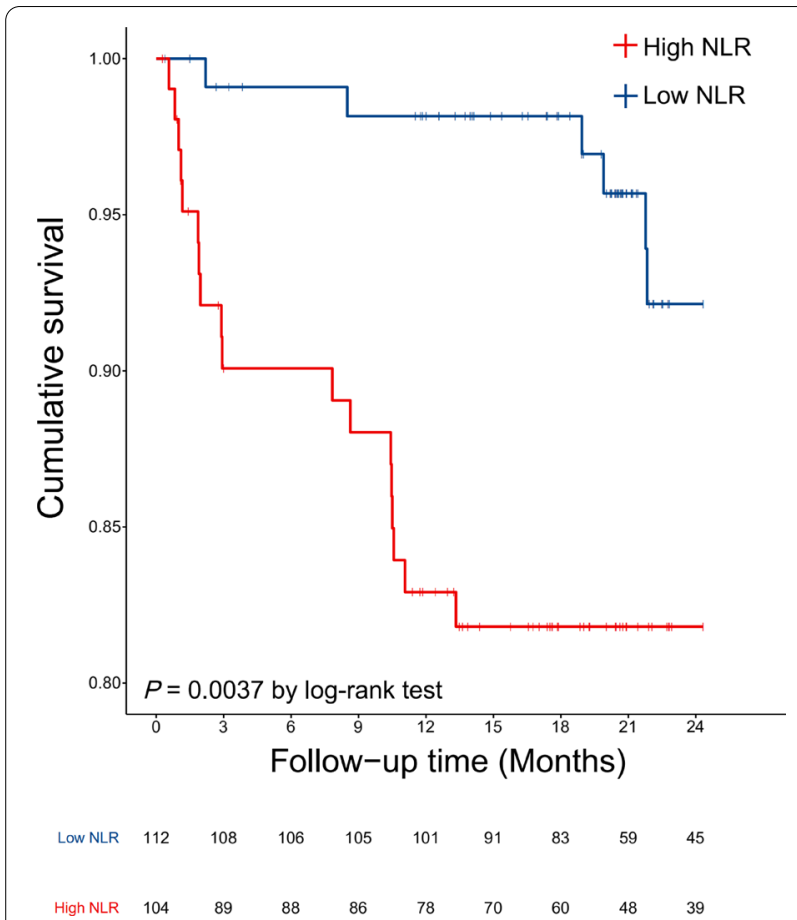

Fig. 1 Kaplan-Meier survival analysis stratified by NLR value 4.8 (low NLR group, < 4.8; high NLR group, $\geq 4.8$ ). The differences between the two groups was assessed with log-rank test. The freedom from early adverse events in the low NLR group was significantly higher than high NLR group $(P=0.004)$. NLR, neutrophil-to-lymphocyte ratio

defined the median NLR 3.5 for all patients as the cutoff value in a retrospective study including 107 patients undergoing thoracic endovascular aneurysm repair. In another study, King et al. [9] used a ROC curve analysis to determine the cut-off value of NLR 4.0 with the highest specificity and sensitivity to correlate with mortality. In the present study, cut-off value 4.8 was obtained using a time-dependent ROC curve associated with 2-year poor outcomes. As NLR is a continuous dynamic value rather than a dichotomous variable, King et al. [9] used a tertile analysis, in which highest NLR group showed poorest outcomes compared with the lower two groups. In our study, effect of NLR per SD change was evaluated in the univariate and multivariable analysis (Table 4). It showed that the risk of early adverse outcomes increased by $98 \%$ for every increase of one SD in preoperative NLR (multivariate HR, $1.98 ; 1.14-3.44 ; P=0.015$ ). Although there is a need to perform experiments with more subjects, this study shows potential risk of early adverse events for UTBAD patients undergoing TEVAR with a higher NLR than 4.8 .
The effect of inflammatory markers in cardiovascular diseases has been studied routinely and a credible relationship between inflammatory markers and cardiovascular diseases has been confirmed [8, 28, 29]. Although the exact mechanisms of these markers are not well understood, it is thought that they reflect the complex interaction between the local immune response at the microenvironment of aortic dissection and the systemic inflammatory response [29-31]. The etiology of $\mathrm{AD}$ is complex, in which inflammation plays an important role [32, 33]. After onset, the systemic response to injury causes neutrophilia and massive neutrophil accumulation in the tunica adventitia of the dissected aorta [34]. The activation of neutrophils and endothelial cell adhesion to generate a large amount of reactive oxygen intermediate, in turn, increasing the vascular endothelial damage, and the excessive consumption of platelets after thrombosis may also increase the risk of aortic dissection rupture [35]. Clinical evidence has confirmed that systemic inflammatory markers like NLR is independently associated with mortality of AD patients [20, 25, 36, 37]. Taken together, inflammatory markers show promise in the diagnosis, timing of treatment and prognosis of $\mathrm{AD}$. However, inflammatory markers are not factored into any risk stratification model of AAD until now [38]. It would be of interest to take the NLR value into consideration of predictive model of AAD for secondary prevention.

\section{Limitations}

Firstly, due to the retrospective study cohort from single center and small number, results may be biased. Secondly, details of adverse events could not be demonstrated via telephone. Thirdly, in clinical practice, however, there remains some controversy regarding the endovascular repair of $\mathrm{UTBAD}$. Although routine TEVAR in UTBAD is standard practice at our institution, different TEVAR procedure manipulations and medical treatment would also affect the results. Fourthly, uTBAD patients who refused to endovascular repair and received optimal medical treatment alone were not included in the study, which may overstate the efficacy of endovascular repair of uncomplicated TBAD. Lastly, anatomic characteristics like oversizing were not included in the analysis, which demand a multi-center study in the future.

\section{Conclusions}

Current study revealed that high preoperative NLR value is an independent risk factor of early adverse events in uTBAD patients undergoing TEVAR. Further studies focused on predictive model combined with NLR value 
Table 4 Univariate and multivariable analysis of 2-year adverse events

\begin{tabular}{|c|c|c|c|c|}
\hline \multirow[t]{2}{*}{ Variable } & \multicolumn{2}{|c|}{ Univariate analysis } & \multicolumn{2}{|c|}{ Multivariate analysis } \\
\hline & $\mathrm{HR}(95 \% \mathrm{Cl})$ & $P$ value & $\mathrm{HR}(95 \% \mathrm{Cl})$ & $P$ value \\
\hline Age & $1.02(1.00,1.07)$ & 0.296 & & \\
\hline Male gender & $0.40(0.13,1.22)$ & 0.105 & $0.49(0.10,2.31)$ & 0.363 \\
\hline BMl & $0.94(0.81,1.11)$ & 0.479 & & \\
\hline Smoking & $0.84(0.23,3.06)$ & 0.792 & & \\
\hline Alcohol & $2.82(0.92,8.61)$ & 0.069 & $0.98(0.23,4.16)$ & 0.980 \\
\hline Hypertension & $1.60(0.44,5.81)$ & 0.476 & & \\
\hline \multicolumn{5}{|l|}{ False lumen patency } \\
\hline Patent false lumen & Reference & & 1 & \\
\hline Partial thrombosis & $0.67(0.15,3.10)$ & 0.608 & $0.50(0.07,3.28)$ & 0.466 \\
\hline Complete thrombosis & $3.43(0.74,15.89)$ & 0.115 & $4.14(0.51,33.35)$ & 0.182 \\
\hline Distance of $\mathrm{LSCA} \leq 2 \mathrm{~cm}$ & $1.02(0.28,3.71)$ & 0.976 & & \\
\hline Maximum diameter of abdominal aorta $(\mathrm{cm})$ & $1.07(0.97,1.18)$ & 0.159 & $1.09(0.92,1.29)$ & 0.316 \\
\hline SBP on admission (mmHg) & $1.00(0.97,1.03)$ & 0.907 & & \\
\hline DBP on admission (mmHg) & $0.91(0.83,0.96)$ & 0.003 & $0.86(0.78,0.95)$ & 0.003 \\
\hline Temperature preoperatively $\left({ }^{\circ} \mathrm{C}\right)$ & $0.64(0.14,2.85)$ & 0.558 & & \\
\hline Creatinine preoperatively $(\mu \mathrm{mol} / \mathrm{l})$ & $1.00(0.98,1.02)$ & 0.741 & & \\
\hline Platelet count preoperatively $\left(\times 10^{9} / \mathrm{l}\right)$ & $0.99(0.99,1.00)$ & 0.107 & & \\
\hline Preoperative NLR per SD & $1.58(1.11,2.26)$ & 0.011 & $1.98(1.14,3.44)$ & 0.015 \\
\hline Alpha-blockers & $3.60(0.47,7.68)$ & 0.219 & & \\
\hline Beta-blockers & $0.95(0.31,2.91)$ & 0.929 & & \\
\hline ARBs & $1.06(0.24,4.79)$ & 0.939 & & \\
\hline ACEls & $1.12(0.23,4.81)$ & 0.939 & & \\
\hline CCBs & $0.47(0.16,1.46)$ & 0.193 & $0.78(0.14,4.40)$ & 0.776 \\
\hline Statins & $0.67(0.21,2.16)$ & 0.497 & & \\
\hline \multicolumn{5}{|l|}{ Timing of procedure } \\
\hline Acute (1-14 days) & Reference & & & \\
\hline Subacute (14-92 days) & $1.16(0.39,3.46)$ & 0.787 & & \\
\hline \multicolumn{5}{|l|}{ ASA classification } \\
\hline 1 & Reference & & Reference & \\
\hline$\|$ & $0.54(0.17,1.77)$ & 0.309 & $0.51(0.10,2.73)$ & 0.433 \\
\hline III & $2.96(0.57,15.36)$ & 0.195 & $3.19(0.22,46.42)$ & 0.395 \\
\hline Adjunctive stents & $3.48(1.07,11.32)$ & 0.038 & $0.79(0.13,4.79)$ & 0.800 \\
\hline
\end{tabular}

HR hazard ratio, $C I$ confidence interval, $B M I$ body mass index, LSCA left subclavian artery, NLR neutrophil-to-lymphocyte ratio, SBP systolic blood pressure, DBP diastolic blood pressure, ASA American Society of Anesthesiologists

should be conducted to open new perspectives in the field of secondary prevention.

\section{Abbreviations}

TEVAR: Thoracic aortic endovascular repair; UTBAD: Uncomplicated type B aortic dissection; IQR: Interquartile range; NLR: Neutrophil-to-lymphocyte ratio; LSCA: Left subclavian artery; COPD: Chronic obstructive pulmonary disease; CAD: Coronary artery disease; TAAD: Type A aortic dissection; EVAR: Endovascular aortic repair; AAA: Abdominal aortic aneurysm; PIS: Post-implantation syndrome.

\section{Acknowledgements}

None.
Authors' contributions

HQZ: Investigation and Writing —original draft. LZ: Writing—original draft. TPL: Writing and Data curation. YML: Data curation. JZ: Writing —review and editing, Supervision. ZPJ: Conceptualization, Project administration.All authors read and approve the final version of the manuscript, and ensure it is the case.

\section{Funding}

The source of funding is the National Natural Science Foundation of China (81700430 and 9173910048) which supported the design of the study, and collection, analysis, interpretation of data, and preparation of the manuscript.

Availability of data and materials

The datasets used and/or analysed during the current study available from the corresponding author on reasonable request. 


\section{Ethics approval and consent to participate}

This retrospective study was approved by the ethical review board of Chang hai Hospital.

\section{Consent for publication}

Not applicable.

\section{Competing interests}

The authors declare that they have no competing interest.

Received: 15 September 2020 Accepted: 3 February 2021

Published online: 16 February 2021

\section{References}

1. Tsai TT, Myrmel T, Smith DE, Llovet A, Distante A, Januzzi JL. Partial thrombosis of the false lumen in patients with acute type B aortic dissection. N Engl J Med. 2007;357(4):349-59.

2. Durham CA, Aranson NJ, Ergul EA, Wang LJ, Patel VI, Cambria RP, Conrad MF. Aneurysmal degeneration of the thoracoabdominal aorta after medical management of type B aortic dissections. J Vasc Surg. 2015;62:900-6.

3. Qin Y-L, Wang F, Li T-X, Ding W, Deng G, Xie B, Teng G-J. Endovascular repair compared with medical management of patients with uncomplicated type B acute aortic dissection. J Am Coll Cardiol. 2016;67:2835-42.

4. Heijmen R, Fattori R, Thompson M, Eggebrecht H, Degrieck I, Nienaber C, Cheshire N. Mid-term outcomes and aortic remodelling after thoracic endovascular repair for acute, subacute, and chronic aortic dissection: the VIRTUE registry. Eur J Vasc Endovasc Surg. 2014;48:363-71.

5. Xiang D, Kan X, Liang H, Xiong B, Liang B, Wang L, Zheng C. Comparison of mid-term outcomes of endovascular repair and medical management in patients with acute uncomplicated type B aortic dissection. J Thorac Cardiovasc Surg. 2019;X:X

6. Tadros RO, Tang GHL, Barnes HJ, Mousavi I, Kovacic JC, Faries P, Olin JW, Marin ML, Adams DH. Optimal treatment of uncomplicated type B aortic dissection. J Am Coll Cardiol. 2019;74:11.

7. Brizuela Sanz JA, González Fajardo JA, Taylor JH, Río Solá L, Muñoz Moreno MF, Vaquero Puerta C. Design of a new risk score in critical limb ischaemia: the ERICVA model. Eur J Vasc Endovasc Surg. 2016:51:90-9.

8. Afari ME, Bhat T. Neutrophil to lymphocyte ratio (NLR) and cardiovascular diseases: an update. Expert Rev Cardiovasc Ther. 2016;14:573-7.

9. King $\mathrm{AH}$, Schmaier $\mathrm{AH}$, Harth $\mathrm{KC}$, Kumins $\mathrm{NH}$, Wong VL, Zidar DA, Kashyap VS, Cho JS. Elevated neutrophil-lymphocyte ratio predicts mortality following elective endovascular aneurysm repair. J Vasc Surg. 2020;72:129-37.

10. Bhutta H, Agha R, Wong J, Tang TY, Wilson YG, Walsh SR. Neutrophillymphocyte ratio predicts medium-term survival following elective major vascular surgery: a cross-sectional study. Vasc Endovasc Surg. 2011;45:227-31.

11. Authors/Task Force members, Erbel R, Aboyans V, et al. 2014 ESC guidelines on the diagnosis and treatment of aortic diseases: document covering acute and chronic aortic diseases of the thoracic and abdominal aorta of the adult the task force for the diagnosis and treatment of aortic diseases of the European Society of Cardiology (ESC). Eur Heart J. 2014;35:2873-926.

12. Lancellotti P, Marechal P, Donis N, Oury C. Inflammation, cardiovascular disease, and cancer: a common link with far-reaching implications. Eur Heart J. 2019;40:3910-2.

13. Tse LW, MacKenzie KS, Montreuil B, Obrand DI, Steinmetz OK. The proximal landing zone in endovascular repair of the thoracic aorta. Ann Vasc Surg. 2004;18:178-85.

14. Zhang L, Lu Q, Zhou J, Jing Z, Zhao Z, Bao J. Alternative management of the left subclavian artery in thoracic endovascular aortic repair for aortic dissection: a single-center experience. Eur J Med Res. 2015;20:57.

15. Trimarchi S, Eagle KA, Nienaber CA, Pyeritz RE, Jonker FHW, Suzuki T, O'Gara PT, Hutchinson SJ, Rampoldi V, Grassi V, Bossone E, Muhs BE, Evangelista A, Tsai TT, Froehlich JB, Cooper JV, Montgomery D, Meinhardt G, Myrmel T, Upchurch GR, Sundt TM, Isselbacher EM. on behalf of the international registry of acute aortic dissection (IRAD) investigators. Importance of refractory pain and hypertension in acute type B aortic dissection: insights from the international registry of acute aortic dissection (IRAD). Circulation. 2010;122:1283-9.

16. Gorla R, Erbel R, Kahlert P, Tsagakis K, Jakob H, Mahabadi A-A, Schlosser T, Eagle K, Bossone E, Jánosi RA. Clinical features and prognostic value of stent-graft-induced post-implantation syndrome after thoracic endovascular aortic repair in patients with type B acute aortic syndromes. Eur J Cardiothorac Surg. 2016:49:1239-47.

17. Nienaber CA, Kische S, Rousseau H, Eggebrecht H, Rehders TC, Kundt G, Glass A, Scheinert D, Czerny M, Kleinfeldt T, Zipfel B, Labrousse L, Fattori R, Ince $\mathrm{H}$. Endovascular repair of type $B$ aortic dissection: long-term results of the randomized investigation of stent grafts in aortic dissection trial. Circ Cardiovasc Interv. 2013;6:407-16.

18. Zhu Y, Luo S, Ding H, Liu Y, Huang W, Xie N, Li J, Xue L, Luo J. Predictors associated with an increased prevalence of postimplantation syndrome after thoracic endovascular aortic repair for type B aortic dissectiont. Eur J Cardiothorac Surg. 2019;55:998-1005.

19. Kordzadeh A, Malietzis G, Browne T, Prionidis I, Panayiotopoulos YP. Neutrophil to lymphocyte ratio (NLR) of five predicts 30-day morbidity in ruptured abdominal aortic aneurysms ( $\mathrm{AAAA}$ ): a retrospective cohort study. Int J Surg. 2015;15:45-8.

20. Lafçi G, ÇiÇek ÖF, Uzun HA, Yalçinkaya A, Diken A, Turak O, Çağli K, Taşoğlu I, GediK HS, Korkmaz K, Günertem OE, Çağli K. Relationship of admission neutrophil-to-lymphocyte ratio with in-hospital mortality in patients with acute type I aortic dissection. Turk J Med Sci. 2014;44:186-92.

21. Bedel C, Selvi F. Association of platelet to lymphocyte and neutrophil to lymphocyte ratios with in-hospital mortality in patients with type A acute aortic dissection. Braz J Cardiovasc Surg. 2019;34(6):694-8.

22. Chen Y, Lin Y, Zhang H, Peng Y, Li S, Huang X. Relationship of platelet counts and inflammatory markers to 30-day mortality risk in patients with acute type A aortic dissection. BioMed Res Int. 2020;2020.

23. Azab B, Zaher M, Weiserbs KF, Torbey E, Lacossiere K, Gaddam S, Gobunsuy R, Jadonath S, Baldari D, McCord D, Lafferty J. Usefulness of neutrophil to lymphocyte ratio in predicting short- and long-term mortality after non-ST-elevation myocardial infarction. Am J Cardiol. 2010;106:470-6.

24. Park JJ, Jang H-J, Oh I-Y, Yoon C-H, Suh J-W, Cho Y-S, Youn T-J, Cho G-Y, Chae I-H, Choi D-J. Prognostic value of neutrophil to lymphocyte ratio in patients presenting with ST-elevation myocardial infarction undergoing primary percutaneous coronary intervention. Am J Cardiol. 2013;111:636-42

25. Appleton ND, Bailey DM, Morris-Stiff G, Lewis MH. Neutrophil to lymphocyte ratio predicts perioperative mortality following open elective repair of abdominal aortic aneurysms. Vasc Endovasc Surg. 2014;48:311-6.

26. Erturk M, Cakmak HA, Surgit O, et al. The predictive value of elevated neutrophil to lymphocyte ratio for long-term cardiovascular mortality in peripheral arterial occlusive disease. J Cardiol. 2014;64(5):371-6.

27. Octeau D, Barnes HJ, Faries CM, Nakazawa KR, Ting W, Marin ML, Faries PL, Tadros RO. Association of preoperative neutrophil-to-lymphocyte ratio with rates of adverse events after thoracic endovascular aneurysm repair. J Vasc Surg. 2020;72:e186.

28. Ueland T, Kjekshus J, Frøland SS, Omland T, Squire IB, Gullestad L, Dickstein K, Aukrust P. Plasma levels of soluble tumor necrosis factor receptor type I during the acute phase following complicated myocardial infarction predicts survival in high-risk patients. J Am Coll Cardiol. 2005;46:2018-21.

29. Bhat T, Teli S, Rijal J, Bhat H, Raza M, Khoueiry G, Meghani M, Akhtar M, Costantino T. Neutrophil to lymphocyte ratio and cardiovascular diseases: a review. Expert Rev Cardiovasc Ther. 2013;11:55-9.

30. Anzai A, Shimoda M, Endo J, Kohno T, Katsumata Y, Matsuhashi T, Yamamoto T, Ito K, Yan X, Shirakawa K, Shimizu-Hirota R, Yamada Y, Ueha S, Shinmura K, Okada Y, Fukuda K, Sano M. Adventitial CXCL1/GCSF expression in response to acute aortic dissection triggers local neutrophil recruitment and activation leading to aortic rupture. Circ Res. 2015;116:612-23

31. Andreata F, Syvannarath V, Clement M, Delbosc S, Guedj K, Fornasa G, Khallou-Laschet J, Morvan M, Even G. Macrophage CD31 signaling in dissecting aortic aneurysm. J Am Coll Cardiol. 2018;72:45-57.

32. Del Porto F, Proietta M, Tritapepe L, Miraldi F, Koverech A, Cardelli P, Tabacco F, De Santis V, Vecchione A, Mitterhofer AP, Nofroni I, Amodeo R, Trappolini M, Aliberti G. Inflammation and immune response in acute aortic dissection. Ann Med. 2010;42:622-9. 
33. Kuehl H, Eggebrecht H, Boes T, Antoch G, Rosenbaum S, Ladd S, Bockisch A, Barkhausen J, Erbel R. Detection of inflammation in patients with acute aortic syndrome: comparison of FDG-PET/CT imaging and serological markers of inflammation. Heart. 2008;94:1472-7.

34. Anzai A. Inflammatory mechanisms contributing to aortic expansion and rupture after acute aortic dissection. J Immunol Sci. 2018;2:22-6.

35. Tsai M-T, Wu H-Y, Roan J-N, Tsai Y-S, Hsieh PCH, Yang Y-J, Luo C-Y. Effect of false lumen partial thrombosis on repaired acute type A aortic dissection. J Thorac Cardiovasc Surg. 2014:148:2140-6.e3.

36. Karakoyun S, Gürsoy MO, Akgün T, Öcal L, Kalçık M, Yesin M, Erdoğan E, Külahçıŏlu S, Bakal RB, Köksal C, Yıldız M, Özkan M. Neutrophil-lymphocyte ratio may predict in-hospital mortality in patients with acute type $A$ aortic dissection. Herz. 2015:40:716-21.

37. Kalkan ME, Kalkan AK, Gündeş A, Yanartaş M, Oztürk S, Gurbuz AS, Ozturk D, Iyigun T, Akcakoyun M, Emiroglu MY, Tuncer MA, Koksal C. Neutrophil to lymphocyte ratio: a novel marker for predicting hospital mortality of patients with acute type A aortic dissection. Perfusion. 2017:32:321-7.

38. Rampoldi V, Trimarchi S, Eagle KA, Nienaber CA, Oh JK, Bossone E, Myrmel T, Sangiorgi GM, De Vincentiis C, Cooper JV, Fang J, Smith D, Tsai T, Raghupathy A, Fattori R, Sechtem U, Deeb MG, Sundt TM, Isselbacher EM. Simple risk models to predict surgical mortality in acute type A aortic dissection: the international registry of acute aortic dissection score. Ann Thorac Surg. 2007;83:55-61.

\section{Publisher's note}

Springer Nature remains neutral with regard to jurisdictional claims in published maps and institutional affiliations.
Ready to submit your research? Choose BMC and benefit from:

- fast, convenient online submission

- thorough peer review by experienced researchers in your field

- rapid publication on acceptance

- support for research data, including large and complex data types

- gold Open Access which fosters wider collaboration and increased citations

- maximum visibility for your research: over $100 \mathrm{M}$ website views per year

At BMC, research is always in progress.

Learn more biomedcentral.com/submissions 